\title{
Sobre la legitimidad de la interrogación meta-filosófica en filosofía de la biología
}

\author{
On the legitimacy of the meta-philosophical interrogation \\ in philosophy of biology \\ E. Joaquín Suárez-Ruíz \\ Universidad Nacional de La Plata, Argentina \\ ernestojoaquinsuarez@gmail.com
}

\begin{abstract}
Resumen
Una de las líneas de investigación más polémicas y actualmente desarrolladas en filosofía de la biología es aquella en la que los/las filósofos/as examinan los supuestos pre-darwinianos que aún estarían presentes en la base de otras sub-disciplinas filosóficas, como ser la ética, la gnoseología, la filosofía del lenguaje, etc. Este tipo de indagación, que aquí denominaré "interrogación meta-filosófica", puede pensarse como un abordaje complementario al epistemológico, el cual permite ampliar el enfoque crítico de la disciplina en cuestión. El objetivo de este artículo será explicitar las características de la "interrogación meta-filosófica" y argumentar sobre su legitimidad en tanto un modo de análisis propio de la Filosofía de la biología.
\end{abstract}

Palabras clave: filosofía de la biología, naturalismo filosófico, meta-filosofía, antropocentrismo.

\begin{abstract}
One of the most controversial and currently developed lines of research in philosophy of biology is that in which philosophers investigate pre-Darwinian assumptions that would still be present at the base of other philosophical sub-disciplines, such as ethics, epistemology, philosophy of language, etc. This type of inquiry, which I will call here "meta-philosophical interrogation," can be thought as a complementary approach to the epistemological one, which allows us to broaden the critical approach of the discipline in
\end{abstract}

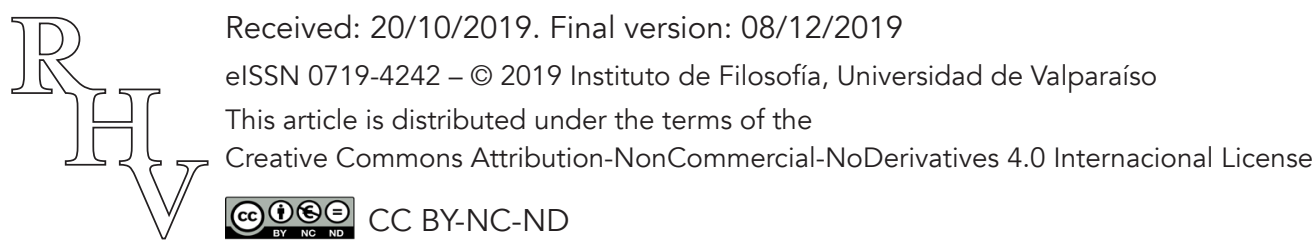


question. The objective of this article will be to analyze the characteristics of the "metaphilosophical interrogation" and to argue about its legitimacy as a way of inquiry proper to the philosophy of biology.

Keywords: philosophy of biology, philosophical naturalism, meta-philosophy, anthropocentrism.

\section{Introducción}

$\mathrm{Al}$ tomar como referencia las producciones actuales de investigadores reconocidos del campo de la filosofía de la biología, el vínculo actual entre filosofía y biología muestra no ser ya exclusivamente el de una aproximación epistemológica. Por señalar algunos ejemplos, cuando Daniel Dennett problematiza la pertinencia del concepto de "libre albedrío" a la hora de comprender el origen y fundamento de la moral (2004), cuando Michael Ruse realiza su crítica meta-ética a las morales sustantivas afirmando que no son sino ilusiones afectivas (2002) o cuando Philip Kitcher (2011) analiza el pasado evolutivo de los seres humanos para desarrollar su Ethical Project, estos filósofos de la biología parten de teorías y estudios biológicos para analizar problemas filosóficos de otras sub-disciplinas, en este caso, de la ética. Todos ellos comparten la convicción de que la visión post-darwiniana $^{1}$ de la evolución de la vida posee profundas implicancias no sólo en la biología sino también en la filosofía.

Este tipo de indagación es realizada por cada vez más filósofos de la biología, pero parece poseer dos puntos problemáticos. En primer lugar, se aleja la convicción de que el único tipo de análisis válido en filosofía de la biología es el de un distanciamiento epistemológico, ya que, para realizar exploraciones de este tipo, el/la filósofo/a precisa comprometerse con conocimientos empíricos a la hora de justificar sus aserciones. Podría argumentarse, por tal, que este compromiso impregnaría dichas investigaciones de un punto de vista acrítico, dogmático y/o reduccionista a la investigación filosófica. El segundo punto problemático reside en que su interrogación avanza no sólo hacia teorías y problemas ajenos a la disciplina de la que parten, sino también hacia los cimientos mismos de esas otras sub-disciplinas que exploran. Por ejemplo, si la crítica de Dennett al concepto de "libre albedrio" pone en duda los fundamentos de la deontología kantiana, el escepticismo meta-ético argumentado por Ruse pone en duda los cimientos mismos de la ética normativa en general.

\footnotetext{
${ }^{1}$ Distingo entre "darwiniano/a" y "post-darwiniano/a" para contemplar, a través de esta última denominación, los múltiples debates actuales en filosofía de la biología que problematizan los principios de la teoría darwiniana clásica.
} 
A pesar de estos dos puntos problemáticos, es a través de este tipo de interrogación que la filosofía de la biología muestra ser capaz de dar cuenta de los posibles aportes y modificaciones que una perspectiva evolutiva de la vida introducen en la filosofía en sentido amplio. Filósofos de la biología como los mencionados, al realizar interrogaciones más osadas con aquellos conceptos y modelos biológicos que en una primera instancia analizaron a través de una lente epistemológica, posibilitan echar nueva luz sobre la serie de problemas y soluciones que constituyen a las diferentes sub-disciplinas filosóficas. De allí que resulte perentorio hallar el modo en que los dos puntos problemáticos mencionados no conduzcan necesariamente a un desprecio absoluto de este tipo de investigaciones.

Así, teniendo presente esta tendencia actual en las producciones vinculadas a la filosofía de la biología, la intención de este artículo será la de exponer una idea, ya esbozada en otros trabajos (Suárez-Ruíz 2017; 2018; 2019), que consiste en lo siguiente: cuando filósofos de la biología como los recién mencionados parten de estudios y teorías provenientes de disciplinas biológicas con el fin de analizar problemas que tradicionalmente pertenecieron al ámbito específico de otras sub-disciplinas filosóficas, exceden el perímetro epistemológico de la filosofía de la biología tradicional para así señalar problemas de tipo meta-filosófico. Es decir, permiten reconocer, examinar y problematizar supuestos pre-darwinianos en otras disciplinas filosóficas y/o tradiciones filosóficas, que quizás estuvieron siendo acarreados a lo largo de su historia canónica.

Este tipo de interrogación meta-filosófica no es nueva en la filosofía contemporánea, dado que pensadores como John Dewey la han realizado ya en las primeras décadas del siglo XX (Dewey 1911). De hecho, según argumenta el especialista Jerome Popp, el pragmatista consideró las implicancias de la teoría darwiniana no sólo en la ética, sino también en la gnoseología (epistemology) y la Política (Popp 2007). Lo novedoso aquí es que, justamente, la interrogación es realizada por filósofos de la biología con una fuerte formación tanto en Epistemología como también (generalmente) en Antropología y Sociología de las ciencias, que los habilitaría a partir de teorías y modelos biológicos con el fin de señalar resabios pre-darwinianos presentes en otras sub-disciplinas, sin por ello perder un enfoque filosófico crítico.

Por tal, este trabajo tiene por objetivo explicitar la existencia de esta interrogación de tipo meta-filosófica generalmente excluida por la ortodoxia en filosofía de la biología, así como también ofrecer argumentos que contribuyan a justificar su legitimidad. Para ello procederé a matizar los dos puntos problemáticos mencionados más arriba. En el segundo apartado analizaré en qué consiste la interrogación meta-filosófica a través de las discusiones vinculadas al "naturalismo filosófico". En el tercero, dado que mi campo de investigación específico es la ética, y que fue a través de los desarrollos ligados a la evolución de la moral por filósofos como los mencionados más arriba que me introduje en las diferentes aristas de la filosofía de la biología, traeré a colación algunas afirmaciones de Michael Ruse respecto de las implicancias meta-éticas del altruismo en términos evo-

Revista de Humanidades de Valparaíso, 2019, No 14, 377-393 
lutivos. Finalmente, en el cuarto apartado argumentaré por qué la filosofía de la biología muestra poseer un rol distinguido en estas interrogaciones de tipo meta-filosóficas a partir del debate filosófico actual en torno al "antropocentrismo".

\section{2. "Naturalismo filosófico" o el punto ciego tras el análisis epistemológico}

Más allá de que existan exploraciones osadas como las que indiqué en la introducción, en filosofía de la biología parece haber una máxima normativa, en muchos casos no justificada y/o formulada de manera manifiesta, que presume que sus investigaciones deben limitarse exclusivamente al análisis epistemológico. Según esta legalidad implícita, aquella investigación filosófica que tomase lo empírico como supuesto para analizar problemas, por ejemplo, éticos, no sería un análisis propiamente filosófico sino uno perteneciente a las ciencias o, incluso, un desvío inconducente. Este supuesto normativo hunde sus raíces en las características de la tradición analítica de la filosofía, centrada ante todo en la clarificación conceptual de las nociones utilizadas en las ciencias. Dicho modo de aproximación tiene la ventaja de evitar comprometer el análisis crítico propio de la filosofía con la carga dogmática de los saberes científicos, pero al mismo tiempo, cuando se supone como el único abordaje filosófico considerado legítimo, tiene la desventaja de vetar al análisis filosófico de los posibles aportes provenientes de las disciplinas científicas.

Para ir a un caso más concreto, la forma en cómo se traduce en filosofía de la biología la tensión recién mencionada es a través de las discusiones en torno al "naturalismo filosófico". Según Michael Ruse, este último podría definirse como el "usar los métodos de las ciencias empíricas o las conclusiones de ellas en nuestras inquisiciones filosóficas" $(2005,96)$. Desde este enfoque, la filosofía se serviría de las ciencias para enriquecer sus investigaciones. Otra definición, ofrecida por el filósofo francés Nicolas Baumard, es la de "una forma de explicar un fenómeno psicológico, social o cultural que sea compatible con las ciencias naturales"” (Baumard 2016, 2). Esta última es más amplia y, sobre todo, más aventurada que la de Ruse, por el hecho de que implica no sólo un uso de los métodos y conclusiones de las ciencias biológicas, sino que, al aseverar que la explicación de los niveles de complejidad de los seres humanos deben coincidir con dichos métodos y conclusiones, podría interpretarse como una propuesta cercana a un reduccionismo de tipo biológico. Esto es, a la pretensión de explicar fenómenos psicológicos, sociales y culturales exclusivamente en términos biológicos (Blackburn 2005, 43). En defensa de la definición propuesta por Baumard (2016), podría argumentarse que, más que advertencias, este tipo de señalamientos representan una falacia de la pendiente resbaladiza (Volokh 2003), por el hecho de que el procurar compatibilidad no supone una exclusividad de la explicación biológica.

\footnotetext{
${ }^{2}$ Las citas seguidas de un asterisco (*) indicarán que la traducción es mía.
} 
Más allá de cualquier definición posible, hay autores que afirman que todo abordaje naturalista de los problemas filosóficos es una empresa desacertada desde un principio. El filósofo de la biología Gustavo Caponi, por ejemplo, afirma:

[...] cuando se habla de 'ética naturalizada' o de 'ética evolucionista', se incurre o bien en un error categorial o bien en un equívoco. El error categorial sería el de confundir cuestiones filosóficas con temas de biología, como sería el caso del estudio de la evolución de nuestras categorías cognitivas y de nuestras pautas morales más básicas. El equívoco, aparentemente menos pernicioso que el error, sería el de aludir a un área de investigación empírica, usando el nombre con el que se designa una reflexión que tiende a la justificación, a la evaluación y a la fundamentación de normas y decisiones. Lo cierto, de todos modos, es que el equívoco es solidario del error y, además, también puede inducirnos a creer que estamos ante una revolución meta-filosófica, cuando en realidad sólo estamos ante un abuso de lenguaje. Lo correcto es hablar, simplemente, de naturalización del pensamiento, de la cognición, de la emotividad, de la sociabilidad, de la moralidad y del gusto. Con ello sólo podríamos entender el estudio biológico de esos temas (Caponi 2018, 186).

Según el filósofo argentino, el abordaje "naturalista" es propio de las ciencias biológicas, por lo que pretender una "naturalización" de la filosofía conlleva los dos desaciertos aquí mencionados: el error categorial del naturalismo filosófico, por un lado, sería el de confundir el ámbito de la filosofía con el de las ciencias naturales y el equívoco, por otro lado, consistiría en confundir el nivel de lo empírico con el de lo epistemológico. Así, apelando a Wittgenstein, el rosarino afirma que un análisis filosófico que procure introducir estudios biológicos como parte integral de su investigación no incurriría sino en un "abuso del lenguaje". Retomaré las aseveraciones categóricas de Caponi en la conclusión.

Sumado a comparar definiciones diversas, otro modo complementario de matizar lo que se entiende por "naturalismo filosófico" es analizar primero el concepto de "naturalismo". Según el filósofo de la biología Antonio Diéguez, no habría algo así como "el" naturalismo ${ }^{3}$, sino que podría hablarse de al menos tres tipos: un naturalismo ontológico, uno epistemológico y uno metodológico. Dado que los dos primeros tienen la desventaja de comprometerse, por un lado, con el supuesto de que es posible conocer de manera invariable las entidades naturales cual esencias fijas (esencialismo en el naturalismo ontológico), y, por otro lado, con el supuesto de que el conocimiento científico permanece constante independientemente de los cambios socio-históricos (cientificismo en el naturalismo epistemológico), Diéguez opta por el naturalismo metodológico como la opción más atinada en la comprensión de cómo y en qué medida reconocerle pertinencia a los conocimientos científicos en el análisis de problemas filosóficos, es decir, a la hora de caracterizar un "naturalismo filosófico". En palabras del filósofo:

\footnotetext{
${ }^{3}$ De hecho, tal como afirma Daniel Andler $(2017,30)$, el conjunto "Naturalistas" podría incluir filosofías tan heterogéneas como las de Leucipo, Aristóteles, Hobbes, Spinoza, Rousseau, Hume, Mill, Dewey, Quine, Strawson, Lewis, Armstrong, Jackson, Dretske o McDowell.
} 
Sobre la legitimidad de la interrogación meta-filosófica en filosofía de la biología

E. Joaquín Suárez-Ruíz

El naturalismo metodológico no sólo es hoy la única opción viable en la ciencia, sino que es visto además por muchos filósofos (entre los que me encuentro) como una opción saludable en la propia práctica de la filosofía. El filósofo que así lo estime, tenderá a creer [...] que no hay diferencias metodológicas que marquen una separación absoluta entre la filosofía y la ciencia —o si se quiere que la filosofía también debe tomar la evidencia empírica como piedra de toque de sus propuestas teóricas, que a su vez han de interpretarse como hipótesis revisables. Aceptará, pues, que en la filosofía puede también aplicarse de forma fructífera un principio de parsimonia - Ronald Giere lo ha bautizado como "principio de prioridad naturalista"- que manda no explicar de forma no naturalista lo que puede ser explicado de forma naturalista (Diéguez 2014a, 40).

Por tal, el naturalismo metodológico tendría siempre presente la advertencia de no perder de vista tanto las limitaciones socio-históricas del cocimiento científico como la imposibilidad de acceder a algo así como "esencias", por lo que abordaría dichos conocimientos siempre a través de un "como si" fuesen ciertos, tendiendo a un principio de parsimonia que busca una complementariedad entre las afirmaciones filosóficas y las investigaciones biológicas del presente. Como puede verse, este enfoque es similar al propuesto por Baumard (2016), sólo que enfatiza las precauciones epistemológicas para con los conocimientos científicos. De modo que, a la luz del desarrollo de Diéguez, gran parte del problema de la "naturalización" de la filosofía parece surgir cuando se supone que sólo hay una manera de comprender el concepto "naturalismo".

La perspectiva del malagueño posibilita, por un lado, conservar un punto de vista crítico en el abordaje de los conocimientos científicos que escapa del esencialismo y/o el cientificismo, al mismo tiempo que, por otro lado, incluye la posibilidad de que dichos conocimientos puedan servir como fundamento a la hora de analizar problemas filosóficos. Desde esta perspectiva, la denominación "ética naturalista", en tanto una disciplina que se incluiría dentro del enfoque del "naturalismo filosófico", no parece ser en sí misma problemática, ya que, siendo que depende de lo que se comprenda por el adjetivo "naturalista", cuando se sigue la vía metodológica defendida por Diéguez esta no converge necesariamente en una visión acrítica, dogmática y/o reduccionista de los conocimientos científicos.

Justamente, un ejemplo de interrogación meta-filosófica a partir de un punto de vista naturalista de la filosofía es el realizado por el filósofo malagueño para el libro Naturaleza animal y humana (Diéguez y Atencia 2014). Allí, Diéguez toma como referencia la filosofía de Donald Davidson para problematizar la idea de que toda creencia tiene contenido proposicional y que, en consecuencia, no habría pensamiento sin lenguaje, analizándola a la luz de la evidencia que permite justificar sólidamente la existencia, al menos en grado, de pensamiento conceptual en primates no humanos. Aludiendo a estudiosos como el psicólogo cognitivo Michael Tomasello (2000) o el biólogo del comportamiento James L. Gould (2002), el filósofo afirma: "No son pocos los investigadores en cognición animal que piensan que para tener conceptos no hace falta tener lenguaje. Para estos investigado-

Revista de Humanidades de Valparaíso, 2019, No 14, 377-393

(c) $(1)(9)$ CC BY-NC-ND 
res no sólo tendría sentido atribuir algún tipo de proto-pensamiento a los animales, sino pensamiento conceptual en toda regla" (Diéguez 2014b, 91). Este sería un ejemplo en el que un filósofo de la biología se aleja del abordaje estrictamente epistemológico, tomando como base evidencias de pensamiento conceptual en animales no-humanos para analizar un supuesto ligado, en este caso no a la ética, sino a la filosofía del lenguaje y a la filosofía del conocimiento.

De hecho, la corrosión de la interrogación que se abre aquí parece ir más lejos: siendo que la idea davidsoniana señalada por Diéguez de la relación entre pensamiento y lenguaje aún puede encontrarse presente como si fuese un supuesto aproblemático en no pocas producciones vinculadas a la tradición analítica ${ }^{4}$, su horizonte de discusión se extiende aún más allá de los fundamentos de una sub-disciplina filosófica particular para llevarla hacia los cimientos de una tradición filosófica. En el cuarto apartado continuaré con este punto.

Para profundizar en las características de la indagación meta-filosófica, en la sección siguiente analizaré un caso en el que un filósofo de la biología analiza cuestiones de ética a la luz de una perspectiva evolutiva post-darwiniana.

\section{Un ejemplo de interrogación meta-filosófica en ética}

La interrogación que subyace al artículo de Michael Ruse denominado Altruismo: una perspectiva naturalista darwiniana es la pregunta sobre el vínculo entre ética normativa, la cual busca determinar qué es lo correcto y qué es lo incorrecto a nivel moral, y meta-ética, la cual analiza los orígenes y características de dicha normatividad, a la luz de una perspectiva naturalista (filosófica). Para ello, Ruse parte del concepto de altruismo desde una perspectiva post-darwiniana ${ }^{5}$. Según él, para comprender el vínculo entre las dos disciplinas mencionadas en el párrafo anterior, es necesario dividir entre un altruismo real, definido como aquel que es percibido en la vida diaria por los seres humanos, es decir, la acción de priorizar a los otros por sobre el beneficio individual (Ruse pone como ejemplo clásico a la Madre Teresa de Calcuta), y un altruismo biológico, esto es, una visión evolutiva del altruismo según la cual este emergió porque de algún modo fue favorecido por la selección natural (Ruse 2005, 99).

A partir de centrar su desarrollo en las características del altruismo biológico en seres humanos, Ruse describe tres formas posibles de comprender los orígenes del altruismo en los seres humanos. La primera forma pone el énfasis en la continuidad, y supone la idea del altruismo como una función innata, similar a cómo se presenta en otras especies fi-

\footnotetext{
${ }^{4}$ Véase, por ejemplo, Lepore y Ludwig (2013).

${ }^{5}$ Dado que mucho se ha debatido ya sobre este concepto desde un enfoque evolutivo, me voy a centrar aquí en los argumentos específicos que aporta el filósofo de la biología, suponiendo cierto conocimiento básico del tópico.
}

Revista de Humanidades de Valparaíso, 2019, No 14, 377-393

(c) (1) @ $\odot$ CC BY-NC-ND 
logenéticamente distantes (el comportamiento altruista entre las hormigas, por ejemplo). La segunda forma pone el énfasis en la discontinuidad, es decir, en las características propiamente humanas. Esta definición comprende al altruismo como un evento surgido exclusivamente por el hecho de que beneficia a los individuos que lo llevan a cabo. Esto es, individuos que a través de un cálculo racional optan por actuar de manera altruista porque es la mejor manera en que garantizan su propia supervivencia. En tercer lugar, y esta es la opción que señala como la más coherente con una perspectiva evolutiva contemporánea, es un punto medio entre las dos anteriores: hay buenas razones para suponer que los individuos no son máquinas súper-calculadoras ni máquinas puramente instintivas sino que, más bien, teniendo en cuenta la influencia fundamental de la cooperación social en la evolución humana, podría afirmarse que existe una base común instintiva, un instinto moral que hace tender hacia el altruismo, pero que permite cierta flexibilidad según el contexto de riesgo y la cercanía parental, y que contempla cierto grado de libertad en el individuo a través de su capacidad racional (Ruse 2005, 101).

Como puede verse, aunque Ruse propone esta tercera vía intermedia como la adecuada a la hora de interpretar evolutivamente el altruismo, su acento está puesto en la continuidad. Ya no de manera desmesurada como sí ocurría en la primera vía, dado que subraya la existencia de una particular flexibilidad en el altruismo de los seres humanos que los diferencias del tipo de cooperación que puede verse presente en otras especies, pero su fundamento es un instinto. Las modificaciones que podrían generar las construcciones racionales se generan siempre variando sobre esta base constante. De allí que relativice la relevancia de los sistemas éticos normativos afirmando que "de hecho, la moral en su mayor parte es justamente una moral del sentido común, más que un sistema bien articulado tal como es producido por filósofos" (Ruse 2005, 104).

Esta concepción instintiva de la moral lo acercaría a una perspectiva humeana. Justamente, otro modo en que señala el instinto fundamental del altruismo en los seres humanos es como un sentido moral (Ruse 2005, 102). Al igual que el filósofo escocés, Ruse ve problemas a la hora de justificar una normatividad fuerte en ética, es decir, al ser la base de la moral un "sentido" proveniente de un instinto y no una capacidad racional consciente, no puede dar cuenta de un criterio incondicional que permita diferenciar de manera unívoca lo moralmente incorrecto de lo correcto. De allí que su análisis converja en un escepticismo ético, según el cual no existirían bases necesarias de la normatividad ética sino que, una vez que se considera con seriedad las consecuencias de un enfoque evolutivo de la moral, buscar un sistema ético objetivo y absolutamente fundado en la razón se presenta como una empresa inviable (Ruse 2005, 106).

Ahora bien, más allá de que la base meta-ética post-darwiniana desarrollada por el filósofo conduce a darle un rol limitado a la racionalidad en la constitución de sistemas éticos, no implica que dicha construcción deje de poseer un efecto importante incluso a pesar de su alcance restringido. Según sus palabras, la posición a la que llega consiste en: "un escepticismo, por favor notar, acerca de fundamentos más que acerca de preceptos

Revista de Humanidades de Valparaíso, 2019, No 14, 377-393 
sustantivos. Lo que estoy diciendo, por lo tanto, es que, debidamente entendida, la aproximación darwiniana a la ética nos lleva a una clase de no-realismo moral"* (Ruse 2005, 106). De modo que su punto de vista de la moral es ante todo descriptivo, vinculado a un planteo meta-ético que matiza la posibilidad de postular morales sustantivas pero sin negarla.

Entonces, su señalamiento de las profundas limitaciones de las construcciones racionales en ética normativa tiene el propósito de sentar las bases de un nuevo comienzo para reiniciar dicha búsqueda. De allí que afirme "[...] defiendo mi noción de altruismo contra la noción algo idealizada que uno encuentra en algunos sistemas morales" (Ruse 2005, 105). Al mismo tiempo, su planteo tampoco elimina la posibilidad de un altruismo radical, como sería, siguiendo su ejemplo, el de la Madre Teresa de Calcuta, sino que, de hecho, tendiendo al extremo quizás se puedan vencer hasta cierto punto las limitaciones (Ruse 2005, 106). A su vez, también rechaza caer cerca de una meta-ética emotivista. Según sus palabras:

Hay una buena razón biológica por la cual hacemos las cosas como las hacemos y sentimos como sentimos. Si, de acuerdo con los emotivistas, pensáramos que la moral es sólo una simple cuestión de emociones sin una sanción o justificación detrás de ellas, entonces la moral muy pronto colapsaría en su futilidad [...] La moral sustantiva se mantiene en su lugar como una ilusión efectiva porque pensamos que no es una ilusión sino algo real. De ese modo, sostengo que el fundamento epistemológico de la ética evolucionista es una clase de no-realismo moral, pero también que una parte importante de la ética evolucionista consiste en que pensemos que es una clase de realismo moral. Ser altruista es una obligación. No es una obligación que existe más allá de la naturaleza humana [...] (Ruse 2005, 107).

Desde una perspectiva idealizada de la ética, es decir, que supone una base absolutamente racional de los juicios morales, afirmar que las razones son "ilusiones efectivas" implicaría caer en un relativismo o un escepticismo total. No obstante, su escepticismo meta-ético no destruye la posibilidad de pensar una moral sustantiva. Si bien la reducción de la jurisdicción de la racionalidad posee importantes consecuencias en lo que respecta a la normatividad, esta capacidad humana aún tendría la posibilidad de, al menos hasta cierto punto, encauzar el sentido moral. De modo que, las características post-darwinianas de la moral no deberían llevar a la comprensión de que todo debate ético es irrelevante, como sí sucedería desde una base emotivista, justamente, por el hecho de que esas "ilusiones" poseen efectos concretos que favorecen la existencia del altruismo real.

Finalmente, hay otro aspecto interesante de su planteo meta-ético post-darwiniano, y es que "sortea" la falacia naturalista de un modo curioso: "no tanto negando que se trata de una falacia sino, por así decirlo, esquivándola. ¡No hay falacia al apelar a la evolución como fundamento porque no hay fundamento al cual apelar! En últimas, el altruismo no tiene bases que lo justifiquen" (Ruse 2005, 107). Nuevamente, la crítica a los sistemas éticos tradicionales no comporta eliminar la normatividad en ética, sino que, de hecho, el 
señalar sus limitaciones podría facilitar su factibilidad o, dicho en otros términos, el "hacerse cargo" de las características evolutivas del altruismo posibilitaría partir de una base más firme a la hora de buscar construcciones racionales efectivas. Por tal, su descripción no-realista de la moral termina por ratificar la relevancia de mantener una pretensión de racionalidad fuerte en ética normativa.

Este análisis de Ruse fue publicado en el año 2002. Desde entonces mucho se ha escrito sobre estos tópicos. Por ejemplo, otra propuesta con la cual se emparenta la perspectiva de Ruse es la del intuicionismo social del psicólogo moral Jonathan Haidt. Este psicólogo es crítico con el modelo racionalista de la moral, según el cual la formación de los juicios morales surge exclusivamente del razonamiento. A través de la inclusión de estudios que suponen una base evolutiva post-darwiniana como los de Frans de Waal (1991) y Antonio Damasio (1994), Haidt gestó el modelo intuicionista social como alternativa al racionalista. Continuar suponiendo en ética, argumenta el psicólogo, que los juicios morales son exclusivamente producto del razonamiento moral implica estar de espaldas a numerosas investigaciones que explicitan la influencia de las intuiciones morales, vinculadas a las emociones, y la relación inter-personal (Haidt 2001, 830). Curiosamente, este psicólogo publicó su primera formulación del modelo un año antes de que Ruse publicara el suyo, no obstante el intuicionismo social es un modelo vigente y próspero en debates actuales (por ejemplo, Brand 2016; Sapolsky 2017).

Otra propuesta emparentada con la propuesta de Ruse es la del filósofo Joshua Greene en su libro Moral Tribes (2013), quien afirma que resulta erróneo reducir toda la dimensión ética humana a una "moral del sentido común" (asimilable al "sentido moral"), más bien, este tipo de moral evolutivamente heredada es la que genera la mayor cantidad de conflictos ético-políticos, por el hecho de que si bien facilita el vínculo Yo-Nosotros, genera grandes dificultades para garantizar el vínculo Nosotros-Ellos. De allí que proponga una ética normativa fundada en una meta-moral que exceda la moral por default a través de la capacidad racional (Green 2013, 25). Más allá de que Ruse ponga el acento en la continuidad a la hora de plantear su escepticismo meta-ético y Greene lo ponga en la discontinuidad en su propuesta normativa meta-moral, ambas teorías resultan, al menos hasta cierto punto, complementarias. Así, la perspectiva de este filósofo sería un ejemplo de cómo una teoría ética que parte de una base evolutiva puede realizar una propuesta normativa.

Teniendo en cuenta estas investigaciones actuales, resulta evidente que el planteo de Ruse sigue poseyendo vigencia, particularmente en cuanto a la pertinencia de pensar una meta-ética post-darwiniana que posibilite generar una ética normativa desde una base "sólida". En la siguiente sección me centraré en las discusiones actuales en torno al "antropocentrismo", dado que este concepto me permitirá resaltar por qué la filosofía de la biología posee un rol fundamental a la hora de realizar indagaciones de tipo meta-filosóficas. 


\section{Antropocentrismo: un "tabú disciplinario"}

Actualmente están en boga las discusiones filosóficas en torno al "antropocentrismo". En ellas, este concepto ya no es tomado en el sentido escolar de la transición renacentista del teocentrismo al antropocentrismo, sino en tanto una antigua idea que se ha convertido en una herencia problemática: la idea de que existe una superioridad de la especie humana que marca una discontinuidad absoluta entre esta y el resto de los seres vivos (Butchvarov $2015,1)$. Aunque a primera vista las perspectivas críticas del antropocentrismo podrían considerarse como fundadas en una preocupación anacrónica, son numerosos los investigadores que argumentan lo contrario.

Gran parte de la producción filosófica vinculada a este concepto se relaciona con la ética animal, particularmente con el concepto de "especismo" popularizado por Peter Singer (2009). Ahora bien, hay otras líneas de investigación ligadas a la crítica al antropocentrismo que no se centran en la ética inter-específica, sino en la intra-específica. Es decir, aquellas que señalan que el antropocentrismo no sólo impide ver relevancia moral en el resto de los seres vivos, sino que también obstaculiza una comprensión en profundidad de las características humanas (de Waal 2007; Boddice 2011; Butcharov 2015).

En sintonía con esta vía de investigación, hay autores que afirman que el antropocentrismo se manifiesta, a su vez, como un obstáculo epistemológico, el cual dificulta la precisión de las explicaciones científicas. Un ejemplo de ello proviene de la discusión en torno al concepto de "cultura" tal como es utilizado en las Humanidades. Los críticos al antropocentrismo señalan que, a pesar de que actualmente se acepta la posibilidad de afirmar la existencia de cultura en animales no humanos (Ingmanson 1996; McGrew 1998; Sapolsky 2004), aún continúa suponiéndose en las disciplinas humanísticas una dicotomía con fuerte carga esencialista. Como bien resume la investigadora Sabrina Tonutti, el enfoque propio de las Humanidades:

a. considera los rasgos culturales humanos bajo una lente de aumento, mientras reduce todos los rasgos animales en una sola categoría, sin tener en cuenta diferencias filogénicas inherentes;

b. ignora / niega elementos de continuidad entre humanos y otras especies animales, etiquetando los signos de la cultura en otros animales como 'proto-cultura', 'pre-cultura', etc., con el objetivo de subrayar la singularidad y superioridad de la especie humana, mientras ignora que cada especie es única y diferenciada según sus particularidades;

c. ignora los vínculos filogénicos entre nuestra especie y otros animales (principalmente primates) [...] Esta oposición se basa en una perspectiva esencialista intrínseca, que supone la existencia de una característica compartida por todos los seres humanos (en este caso la cultura), que es capaz de distinguir cualitativamente a los humanos de todas las demás especies animales.* (Tonutti 2011, 185).

Revista de Humanidades de Valparaíso, 2019, No 14, 377-393 
Según Tonutti, habría un resabio esencialista que traza una diferencia radical entre, por un lado, la cultura de todos los seres humanos y, por otro lado, la cultura de todos los animales no humanos ${ }^{6}$. Por lo que, más allá de que incluso al interior de las Humanidades pueda llegar a aceptarse la presencia de cierto tipo de cultura no humana, permanecería una suerte de tabú disciplinario que impide profundizar en ello (Tounutti 2011, 198). Según el punto de vista antropocéntrico, el sólo hecho de poner el acento explicativo en la continuidad inevitablemente conllevaría caer en un reduccionismo biológico (nuevamente, la falacia de la pendiente resbaladiza pareciese ser una "justificación" recurrente cuando se aspira a problematizar la tendencia antropocéntrica de las disciplinas humanísticas). El obstáculo epistemológico reside en que, justamente, esta aversión a la continuidad en las Humanidades termina perpetuando el supuesto pre-darwiniano de una separación radical entre dos ámbitos homogéneos.

Vinculado a la crítica epistemológica, el filósofo contemporáneo Jean-Marie Schaeffer caracteriza al antropocentrismo como una "Tesis de la excepción humana" (TEH), cuya matriz fue forjada en la modernidad (particularmente a partir de la filosofía cartesiana), y que es aún reproducida al interior de las Humanidades (Schaeffer 2009). Dicha tesis estaría constituida por cuatro postulados que proliferan de manera constante e implícita en el análisis humanístico. De manera resumida, estos se caracterizan por: 1 - Una "ruptura óntica" que separa radicalmente a los seres humanos de las otras formas de vida; 2 - Un dualismo entre un orden "natural" y otro "espiritual", según el cual los seres humanos quedarían exclusivamente en el segundo ámbito; 3 - Una concepción gnoseocéntrica que instaura la actividad racional como la característica humana por excelencia; 4 - Y, finalmente, un "ideal cognitivo anti-naturalista", esto es, la ruptura y el dualismo instauran la idea de que es posible prescindir de todo "lo natural" en la pregunta por "lo humano" (Schaeffer 2009, 24-25).

Para un filósofo de la biología ortodoxo, particularmente aquel formado en la tradición analítica, la advertencia de Schaeffer sonaría como algo sumamente forzado, por el hecho de que el filósofo francés estaría señalando un extravagante problema "metafísico" donde en realidad no existe. La TEH, si se la considerase a la luz de disciplinas científicas como la biología evolutiva, mostraría ser más un "abuso del lenguaje" que una advertencia relevante. Paralelamente, seguramente le llamaría la atención que el "antropocentrismo" sea un tópico tan en boga en las producciones filosóficas de la actualidad. Siendo que la teoría de la evolución, al menos en sus aspectos más básicos, es aceptada por toda (o casi toda) la comunidad académica, el suponer que subsiste la idea de una discontinuidad absoluta, análoga a la que suponían los naturalistas pre-darwinianos, no tendría ninguna vigencia.

En defensa del enfoque de Schaeffer es posible afirmar que esa lectura no hace justicia de su análisis, dado que lo interpreta desde una concepción disciplinal que, justamente,

\footnotetext{
${ }^{6}$ La costumbre extendida en las producciones humanísticas a entrecomillar la palabra "naturaleza" y sus derivados, pero no la de "cultura", parece ser otro indicio de ello.
} 
no puede ver el dogma que perpetua. El aporte principal del filósofo francés reside en que no plantea la TEH como un problema empírico o científico, sino que libra la discusión en los fundamentos mismos de la disciplina "filosofía", es decir, propone una pesquisa que problematice los supuestos pre-darwinianos que aún podrían seguir siendo reproducidos a nivel disciplinal. Su análisis pone el foco en las Humanidades en general y en la filosofía en particular como disciplinas herederas y reproductoras de supuestos aún no problematizados, institucionalmente perpetuados, de los cuales el principal es la idea de una discontinuidad radical de lo humano. Lo que sucede con el concepto de "cultura" desarrollado por Tonutti, sería un ejemplo de esta tenacidad a nivel institucional.

Tomando nuevamente como ejemplo el desarrollo de Diéguez, la visión davidsoniana del pensamiento conceptual elimina ya desde su punto de partida la posibilidad de que exista pensamiento sin lenguaje y, por tal, de pensamiento conceptual en animales no humanos. Actualmente numerosas investigaciones permiten problematizar la validez de este supuesto (Sterelny 2006; Toribio 2010; Toda y Platt 2015), por lo que la filosofía de este autor norteamericano, al menos en lo que respecta al aspecto mencionado, muestra poseer algunos dogmas que hoy se reconocen como obsoletos o, como mínimo, dudosos. Por tal, continuar reproduciendo ese aspecto del enfoque davidsoniano como aproblemático tiene como consecuencia mantener una visión pre-darwiniana del vínculo entre pensamiento y lenguaje. A pesar de ello, y como se mencionó en la primera sección, aún suele considerarse que este punto de vista posee aún perfecta vigencia.

Llegados a este punto, me permito arriesgar una hipótesis: la ortodoxia en filosofía de la biología que considera como único análisis legitimo el epistemológico, corre el riesgo de perpetuar supuestos pre-darwinianos en otras sub-disciplinas e, incluso, en tradiciones filosóficas a las cuales los mismos filósofos de la biología podrían estar adscribiendo de manera acrítica. Dichos supuestos pre-darwinianos suelen ser reproducidos sin otra justificación más que la apelación a una tradición y/o a autores canónicos (Wittgenstein, Davidson o Carnap serían algunos ejemplos de ello). De modo que, tras el pretendido "purismo" de lo epistemológico que niega pertinencia a la interrogación meta-filosófica podrían estar siendo perpetuados y/o reproducidos supuestos dogmáticos no reconocidos como tales. Según lo que se desarrolló en este artículo, la carga de la prueba quedaría del lado, no de los/las filósofos/as de la biología que se aventuran en el análisis de problemas éticos o gnoseológicos desde una perspectiva evolutiva, sino de los representantes de la ortodoxia que, a través del hábito anquilosado de una constante apelación a la autoridad, implícita o explícita, corren el riesgo de perpetuar supuestos pre-darwinianos por detrás de la idea de una legitimidad exclusiva de lo epistemológico.

Yendo aún un poco más lejos podría decirse que escrutinios como los realizados por Diéguez, Ruse, Tonutti o Schaeffer permiten poner en duda el concepto de "naturalismo filosófico", pero esta vez no para rechazarlo, sino para examinar si acaso se trata de un enfoque más, como pueden ser el de la "fenomenología" o el del "existencialismo". Es decir, teniendo en cuenta las profundas implicancias que muestra poseer la interrogación 
meta-filosófica, de lo que se trata aquí no es ya de una corriente filosófica entre otras, sino de un tipo de interpelación profunda que explicita supuestos problemáticos presentes en la base de las múltiples sub-disciplinas filosóficas y, aún más, de las tradiciones filosóficas en sí mismas. El "naturalismo filosófico" se revela, en realidad, como meta-filosofía.

Antes de finalizar preciso mencionar una posible objeción a la interrogación meta-filosófica, la cual, expresada en forma de pregunta, sería algo como ¿Por qué la filosofía de la biología debería comprenderse, a su vez, como una suerte de "biofilosofía"? La respuesta sería que, justamente, una investigación filosófica no puede nunca dejar de poseer un distanciamiento crítico para con el objeto que analiza, ya que, de otra manera, se convertiría en un ámbito propicio para la reproducción de dogmas. De allí que la interrogación meta-filosófica sea complementaria del análisis epistemológico, por el hecho de que suponer este tipo de indagación como independiente de la lente problematizadora propia de la filosofía de la biología implicaría correr el riesgo de perder de vista las múltiples limitaciones del conocimiento científico. Es decir, siendo que resulta imprescindible cierto compromiso para con estudios y modelos científicos en la búsqueda de supuestos dogmáticos pre-darwinianos, resulta imprescindible la lupa crítica de lo epistemológico.

Así, al considerar que tanto el análisis epistemológico como la interrogación meta-filosófica forman parte de una sola disciplina, es la capacidad crítica de la filosofía de la biología la que se enriquece. No sólo por el aumento de complejidad con el cual puede abordar su objeto (la biología), sino porque uno funciona como precaución metodológica del otro. Esto es, así como el análisis epistemológico habilita una visión crítica de los estudios empíricos y las teorías biológicas, la interrogación meta-filosófica permite una revisión de los supuestos de neutralidad e imparcialidad que podrían estar siendo reproducidos de forma subyacente en las sub-disciplinas y/o tradiciones filosóficas.

\section{Conclusiones}

Soy consciente de que en este artículo introduje varias ideas arriesgadas y heterodoxas: la "interrogación meta-filosófica", el naturalismo filosófico en tanto meta-filosofía y la TEH como perpetuada por la filosofía de la biología seguramente sean los planteos que más mohines podrían generar. Tal como señalé en la introducción, mi propósito es ante todo práctico: por un lado explicitar la existencia del tipo de interrogaciones meta-filosóficas realizadas por filósofos de la biología como Diéguez y Ruse y, por otro lado, argumentar sobre su legitimidad como un modo de indagación propio de la filosofía de la biología en tanto disciplina.

A la luz de lo desarrollado, se resuelven los dos puntos problemáticos mencionados en la introducción. En relación con el primero, la interrogación meta-filosófica muestra no sólo escapar del dogmatismo, sino también ampliar el enfoque crítico. Es decir, a través del potencial meta-filosófico de investigaciones biológicas que fundamentan el 
pensamiento conceptual en primates no humanos o el origen evolutivo del altruismo, es posible señalar críticamente dogmatismos pre-darwinianos no reconocidos como tales al interior de las sub-disciplinas y/o tradiciones filosóficas. Dada su relevancia fundamental, y en relación con el segundo punto problemático, esta indagación "entrometida" de la filosofía de la biología debería salir de su rol marginal en notas al pie o en especulaciones recreativas de filósofos reconocidos. Utilizando una analogía, si el análisis epistemológico puede entenderse como un reflector que se dirige hacia los estudios, teorías y modelos científicos, la interrogación meta-filosófica sería la que permite girar su farol $180^{\circ}$ para así echar luz sobre los supuestos dogmáticos que podrían permanecer impertérritos en la base de la filosofía misma.

Volviendo al planteo de Caponi mencionado en la primera sección, ni el equívoco ni el error categorial muestran ser tales. Respecto del primero, si acaso se pretende poseer una visión crítica y problematizadora tanto de la biología como de la filosofía misma, el análisis epistemológico y la indagación meta-filosófica deberían comprenderse como abordajes complementarios e interdependientes entre sí. Respecto del segundo, y como consecuencia de lo recién afirmado, continuar suponiendo una distinción radical entre los ámbitos de la filosofía y de la biología, particularmente en lo referido al análisis filosófico de las características de la evolución humana, conlleva perpetuar y/o reproducir supuestos pre-darwinianos que aún pueden encontrarse en la base de las sub-disciplinas y/o tradiciones filosóficas. Es decir, el no comprometerse en absoluto para con modelos y teorías biológicas a la hora de hacer filosofía, incluye la posibilidad de sí comprometerse con dogmatismos más vetustos, afincados y menos obvios que esos modelos y teorías.

Finalmente, habiendo evidenciado las características corrosivas de la indagación meta-filosófica y teniendo en cuenta que es un tipo de análisis presente incluso desde las primeras décadas del siglo XX, es posible afirmar que no se trata de una "revolución meta-filosófica" o una tendencia pasajera, sino de una inquietud propiamente filosófica de larga data que actualmente se encuentra en proceso de afianzamiento disciplinal. Es por ello que resulta capital que los filósofos y las filósofas de la biología, en lugar de considerar este tipo de interrogaciones como pasatiempos especulativos o como no dignos de su disciplina, se comprometan en este tipo de discusiones, justamente, tanto para continuar con el análisis crítico de las ciencias biológicas como también para descomprometerse de dogmatismos filosóficos arcaicos que quizás se encuentren persistiendo en la base de sus investigaciones.

\section{Agradecimientos}

El autor agradece al Consejo Nacional de Investigaciones Científicas y Técnicas (CONICET) y a la Universidad Nacional de La Plata por el apoyo financiero. También agradece especialmente al Dr. Martín Daguerre y al Dr. Leonardo González Galli por la revisión crítica del artículo. 
Sobre la legitimidad de la interrogación meta-filosófica en filosofía de la biología

E. Joaquín Suárez-Ruíz

\section{Referencias bibliográficas}

Andler, D. (2016). La silhouette de l'humain. Quelle place pour le naturalisme dans le monde d'aujourd'hui? Paris: Gallimard.

Baumard, N. (2016). The origins of fairness, how evolution explains our moral nature. Oxford: Oxford University Press.

Blackburn, S. (2005). The oxford dictionary of philosophy. Oxford: Oxford University Press.

Boddice, R. (ed.) (2011). Humans, animals, environments. Leiden: Brill.

Brand, C. (ed.) (2016). Dual-process theories in moral psychology. Wiesbaden: Springer.

Butcharov, P. (2015). Anthropocentrism in philosophy. Berlin: De Gruyter.

Caponi, G. (2018). ¿Qué quiere decir “naturalizar”? Ludus Vitalis, XXVI(50): 185-188.

Damasio, A. (1994). Descartes'error: emotion, reason, and the human brain. New York: Putnam.

Dennett, D. (2004). La evolución de la libertad. Barcelona: Paidos.

Dewey, J. (1911). The influence of Darwin on Philosophy. The Philosophical Review, 20(2): 219221.

Diéguez, A. (2014a). Delimitación y defensa del naturalismo metodológico (en la ciencia y en la filosofía). En R. Gutierrez-Lombardo, J. Sanmartín (eds.), La filosofia desde la ciencia, pp.21-49. México DF: Centro de Estudios Filosóficos, Políticos y Sociales Vicente Lombardo Toledano.

Diéguez, A. (2014b). Pensamiento conceptual en animales. En A. Diéguez, J. M. Atencia, Naturaleza animal y humana, pp. 83-114. Madrid: Biblioteca nueva.

Diéguez, A., Atencia, J. M. (2014). Naturaleza animal y humana. Madrid: Biblioteca nueva.

Gould, J. L. (2002). Learning instincts. En J. Wixted, H. Pashler (eds.), Steven's handbook of experimental psychology: Learning, motivation, and emotion, pp. 239-257. New Jersey: John Wiley \& Sons. doi: https://doi.org/10.1002/0471214426.pas0306

Greene, J. (2013). Moral tribes. Nueva York: The Penguin Press.

Haidt, J. (2001). The emotional dog and its rational tail: a social intuitionist approach to moral judgment. Psychological Review, 108: 814-834.

Ingmanson, E. (1996). Tool-using behavior in Wild Pan Paniscus: Social and Ecological Considerations. En A. Russon et al. (eds.), Reaching into Thought: The Minds of the Great Apes, pp. 190-210. Nueva York : Cambridge University Press.

Kitcher, P. (2011). The ethical Project. Cambridge: Harvard University Press.

Lepore, E., Ludwig, K. (eds.) (2013). A companion to Donald Davidson. Oxford: Wiley-Blackwell.

McGrew, W. (1998). Culture in nonhuman primates? Annual Review of Anthropology, 27: 301-28.

Revista de Humanidades de Valparaíso, 2019, No 14, 377-393

(c) $(1) \Theta(-)$ CC BY-NC-ND 
Popp, J. (2007). Evolution's first philosopher, John Dewey and the continuity of nature. Nueva York: State University of New York Press.

Ruse, M. (2005). Altruismo: una perspectiva naturalista darwiniana. Saga, 10: 95-110. Traducción: Maximiliano Martínez y Fernando Melo. El texto original puede hallarse en S. Post, et al. (eds.) (2002), Altruism and altruistic love. Oxford: Oxford University Press.

Schaeffer, J. M. (2009). El fin de la excepción humana. Barcelona: Marbot.

Sapolsky, R. (2017). Behave: the biology of humans at our best and worst. Nueva York: Penguin.

Sapolsky, R., Share, L. (2004). A pacific culture among wild baboons, its emergence and transmission. Public Library of Science Biology, 2: e106-13.

Singer, P. (2009). Liberación Animal. Madrid: Trotta.

Sterelny, K. (2006). Folk logic and animal rationality. En S. Hurley, M. Nudds (eds.), Rational Animals? pp. 293-311. Oxford: Oxford University Press.

Suárez-Ruíz, E. J. (2017). Filosofía post-darwiniana: sobre la relevancia de la continuidad evolutiva en la comprensión de la moral. Tesis de licenciatura, Dpto. de Filosofía, FaHCE, UNLP.

Suárez-Ruíz, E. J. (2018). Para una caracterización filosófica de la continuidad evolutiva. Revista Latinoamericana de Estudios Críticos Animales, 2: 139-158.

Suárez-Ruíz, E. J. (2019). El otro lado de la filosofía de la biología: una problematización de lo epistemológico como límite disciplinar. Nuevo Itinerario, 15: 58-74.

Toda, K., Platt, M. L. (2015). Animal cognition: monkeys pass the mirror test. Current biology, 25(12): 64-66.

Tomasello, M. (2000). Primate cognition: introduction to the issue. Cognitive science, 24(3): 351-361.

Toribio, J. (2010). The animal concepts debate: a metaphilosophical take. Teorema, XXIX(2): 11-24.

Tonutti, S. (2011). Anthropocentrism and the Definition of 'Culture' as a Marker of the Human/ Animal Divide. R. Boddice (ed.), Humans, Animals, Environments, pp.183-199. Leiden: Brill.

Volokh, E. (2003). The mechanisms of the slipperly slope. Harvard Law Review, 116(4): 10261137.

Waal, F. de (1991). The chimpanzee's sense of social regularity and its relation to the human sense of justice. American Behavioral Scientist, 34: 335-349.

Waal, F. de (2007). Primates y filósofos. Barcelona: Paidos. 
